\title{
Combination of the Ross II operation with stentless bioprosthesis and radiofrequency maze IV operation
}

Jen-Ping Chang, MD, Hung-I Lu, MD, Chiung-Lun Kao, MD, Ming-Shian Lu, MD, and Ming-Jang Hsieh, MD, Taiwan, Republic of China

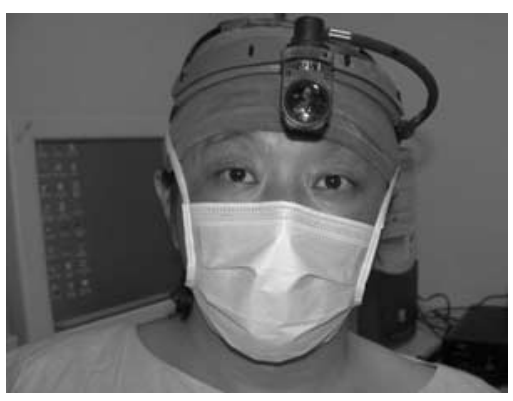

Dr Chang
T he search for an ideal mitral valve substitute continues. Ross ${ }^{1}$ described the use of a pulmonary autograft for mitral valve replacement in 1967, and this operation is only now being reappraised because of its many advantages. ${ }^{2,3}$ In patients with irreparable mitral valvulopathy complicated with chronic atrial fibrillation, addition of some sort of ablative procedure has been recommended to make its benefits more complete. ${ }^{4}$ Currently, a stentless bioprosthesis is accepted as the right ventricular outflow tract (RVOT) substitute of choice in the Ross procedure. ${ }^{4,5}$ We report on 2 patients who had satisfactory results with the use of a Freestyle aortic root bioprosthesis (Medtronic, Inc, Minneapolis, Minn) for RVOT reconstruction in the Ross II procedure combined with the radiofrequency maze IV procedure that was developed in our center.6,7

\section{Clinical Summaries}

PATIENT 1. A 48-year-old man with history of severe rheumatic mitral stenosis, chronic atrial fibrillation, and left atrial thrombi demonstrated by 2-dimensional echocardiography was referred to us. He had just recovered from massive duodenal ulcer bleeding and multiple cerebral hemorrhagic infarctions related to anticoagulation therapy, complicated by acute respiratory failure 1 month previously. Mechanical prostheses were apparently contraindicated, whereas xenograft bioprostheses would be expected to degenerate and calcify early because of the relatively young age of the patient. The ablative procedure for the chronic atrial fibrillation was another issue for this particular patient, as was avoidance of lifelong anticoagulation.

\footnotetext{
From the Division of Thoracic and Cardiovascular Surgery, Chang Gung Memorial Hospital at Kaohsiung, Taiwan, Republic of China.

Received for publication April 9, 2002; accepted for publication April 23, 2002.

Address for reprints: Jen-Ping Chang, MD, Division of Thoracic and Cardiovascular Surgery, Chang Gung Memorial Hospital at Kaohsiung, 123, Ta-Pei Rd, Niao Sung Hsiang, Kaohsiung Hsien, Taiwan, Republic of China (E-mail: c9112772@adm.cgmh.org.tw).

J Thorac Cardiovasc Surg 2002;124:1252-3

Copyright $\odot 2002$ by The American Association for Thoracic Surgery

$0022-5223 / 2002 \$ 35.00+0 \quad \mathbf{1 2 / 5 4 / 1 2 6 0 4 2}$

doi: $10.1067 / \mathrm{mtc} .2002 .126042$
}

The patient was operated on with the use of routine cardiopulmonary bypass and antegrade oxygenated cold crystalloid cardioplegia. The mitral valve showed a fish-mouth appearance, with rigid leaflets and completely fused subvalvular apparatus. The left atrium was filled with thrombi and diffusely calcified. The pulmonic valve was harvested and implanted inverted in the mitral position inside a 26-mm Dacron polyester fabric tube as the "top hat." 8 The RVOT was reestablished with a $27-\mathrm{mm}$ Freestyle bioprosthesis and bovine pericardial patch reconstruction of the posterior wall defect, which was created after the pulmonic valve harvesting (Figure 1). The left atrial thromboendatriectomy and radiofrequency maze IV procedure were done.

The patient recovered uneventfully and was discharged 10 days after the operation in stable sinus rhythm. Follow-up transesophageal echocardiography 3 months after the operation confirmed the competent pulmonary autograft in the mitral position without pressure gradient. The patient has been drug free since then.

PATIENT 2. A 44-year-old woman with a history of progressive shortness of breath and abdominal distention and atrial fibrillation for 2 years. She had undergone percutaneous transluminal mitral commissurotomy 9 years previously, with suboptimal results for her severe rheumatic mitral stenosis. Repeated transthoracic echocardiography revealed recurrent severe calcified mitral stenosis and tricuspid regurgitation. Because of the patient's age and her refusal of permanent anticoagulation, we decided to use the patient's own pulmonic valve.

The patient was operated on with the use of routine cardiopulmonary bypass and antegrade oxygenated cold crystalloid cardioplegia. The mitral valve appearance was consistent with rheumatic valvulopathy, with both leaflets severely thickened and calcified. The anterolateral commissure was well split, but it was impossible to repair the valve because of the thickened and fused subvalvular apparatus. The top hat technique was used as previously described for patient 1 . The radiofrequency maze IV procedure and tricuspid valve repair were also done.

The patient recovered uneventfully and was discharged 12 days after surgery in stable sinus rhythm. Follow-up transesophageal echocardiography 3 months after the operation showed trivial pulmonary autograft regurgitation in the mitral position (Figure 2) without pressure gradient. The patient has been drug free since that time. 


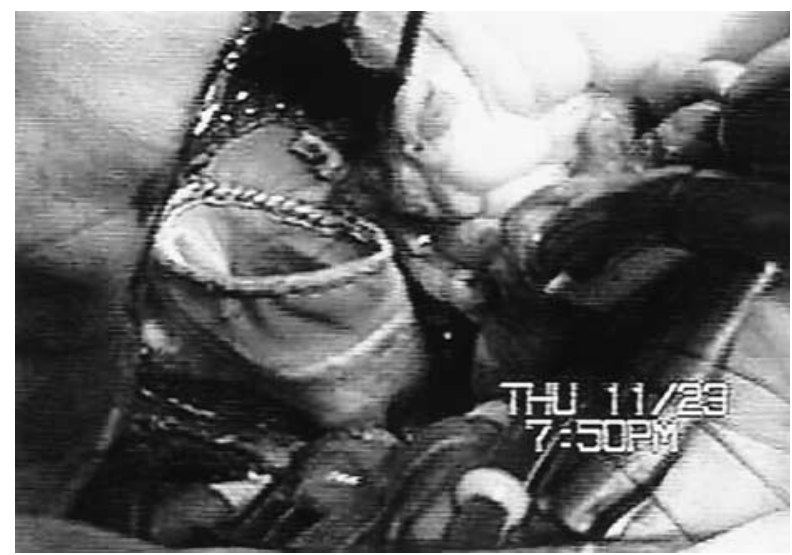

Figure 1. RVOT was reestablished with 27-mm Freestyle bioprosthesis and bovine pericardial patch reconstruction of posterior wall defect, which was created after pulmonic valve harvesting.

\section{Discussion}

Mitral repair is preferable but not always feasible, especially for patients with complex rheumatic valvulopathy. Valve replacement with a mechanical prosthesis or bioprosthesis is not without drawbacks. The search for an ideal mitral substitute continues. Ross ${ }^{1}$ described the use of a pulmonary autograft for mitral valve replacement in 1967 , and this operation is now being reappraised because of its many advantages. ${ }^{2,3}$ Autografts show excellent longevity, have clear hemodynamic superiority, are infection resistant, and do not necessitate anticoagulation. These characteristics are attractive, even though the procedure is complex and time-consuming. Although there have been several modifications, ${ }^{4,9}$ we prefer the top hat technique, ${ }^{8}$ because we believe that the proximal pericardial collar fixation is important to prevent instability or deformity in this fully flexible tubing graft. Whether the pulmonic valve is restrained within a prosthetic tube graft seems less important. Because the entire autograft is buried within the left atrial wall, the role of the autograft sinuses must be not as important as the autograft in the aortic position.

Currently, a pulmonary homograft is preferred worldwide as the RVOT substitute in the Ross procedure. The lack of pulmonary homograft limits the use of the pulmonary autograft in many parts of the world. Recently, a stentless bioprosthesis has been accepted as the RVOT substitute in the Ross procedure. ${ }^{4,5}$ In this report, we demonstrate that the use of a Freestyle aortic root bioprosthesis for RVOT reconstruction in the Ross II procedure is feasible with satisfactory results, at least in the short term.

Pericardial patch reconstruction of the RVOT posterior wall defect, which was created after the pulmonic valve harvesting, is a minor technique for effective hemostasis. This modification also plays an important role for the strong RVOT reconstruction.

Kabbani and coworkers ${ }^{4}$ have recommended that some sort of ablative procedure be added to the Ross II procedure when treating patients with chronic atrial fibrillation, to make the benefits of the procedure more complete. The radiofrequency maze IV procedure, which was developed in our center, has provided promising longterm results. This procedure can be performed with less bleeding than the classic Cox maze procedure, and it is both less timeconsuming and less technically demanding.6,7

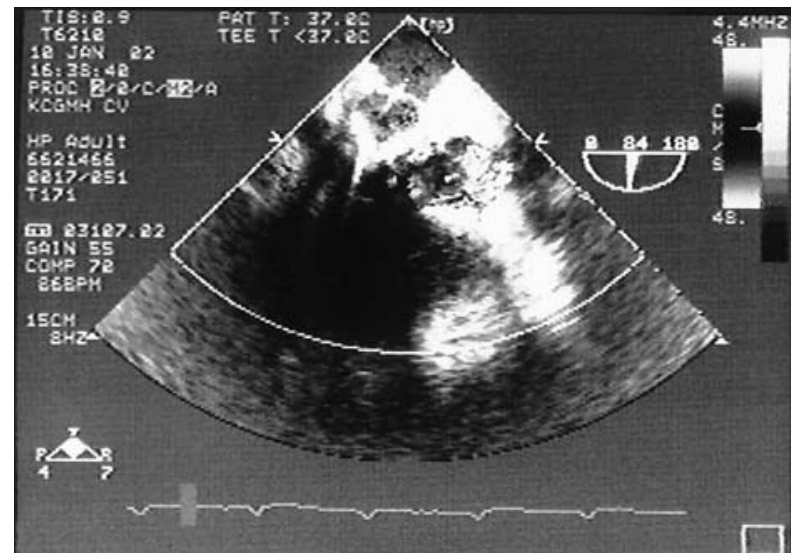

Figure 2. Follow-up transesophageal echocardiogram 3 months after operation shows trivial pulmonary autograft regurgitation in mitral position.

Aortic valve replacement with the pulmonary autograft is a promising option. In contrast, the use of the pulmonary autograft in the mitral position has been mentioned only in limited articles. ${ }^{1-4,8,9}$ Nevertheless, Ross and Kabbani ${ }^{8}$ have demonstrated that the pulmonic valve could function well inverted in the mitral position for as long as 14 years.

In conclusion, although the potential for growth is lost when the pulmonary autograft is used as the top hat, many advantages, such as the excellent longevity, clear hemodynamic superiority, infection resistance, and lack of anticoagulation needs, make the Ross II procedure worthy of reappraisal. This is especially true when the radiofrequency maze IV procedure is added to this operation in patients with chronic atrial fibrillation. In such cases, the surgeon may achieve a cure for these challenging patients.

\section{References}

1. Ross DN. Replacement of aortic and mitral valves with a pulmonary autograft. Lancet. 1967;2:956-8.

2. Kabbani SS, Ross DN, Jamil H, Hammound A, Nabhani F, Hariri R, et al. Mitral valve replacement with a pulmonary autograft: initial experience. J Heart Valve Dis. 1999;8:359-67.

3. Al Hales ZA, Awad MM, Pielers F, Shahid MS, Al Amri MA. Six-year follow-up of a pulmonary autograft in the mitral position: the Ross II procedure. J Thorac Cardiovasc Surg. 1999;117:614-6.

4. Kabbani SS, Jamil H, Hammound A. Technique for replacing the mitral valve with a pulmonary autograft: the Ross-Kabbani operation. Ann Thorac Surg. 2001;72:947-50.

5. Konertz W, Sidiropoulos A, Hotz H, Borges A, Baumann G. Ross operation and right ventricular outflow tract reconstruction with stentless xenografts. J Heart Valve Dis. 1996;5:618-20.

6. Chen MC, Guo BF, Chang JP, Yeh KH, Fu M. Radiofrequency and cryoablation of atrial fibrillation in patients undergoing valvular operations. Ann Thorac Surg. 1998;65:1666-72.

7. Chen MC, Chang JP, Guo BF, Chang HW. Atrial size reduction as a predictor of the success of radiofrequency maze procedure for chronic atrial fibrillation in patients undergoing concomitant valvular surgery. J Cardiovasc Electrophysiol. 2001;12:867-74.

8. Ross DN, Kabbani S. Mitral valve replacement with a pulmonary autograft: the mitral top hat. J Heart Valve Dis. 1997;6:542-5.

9. Kumar AS, Aggarwal S, Choudhary SK. Mitral valve replacement with the pulmonary autograft: the Ross II procedure. J Thorac Cardiovasc Surg. 2001;122:378-9. 